Estima, D.C.; Martins, F.M.C.P.F.; Rabinovici, A.; Ventura, M.A.M. A atuação das Organizações Não-Governamentais ambientalistas no turismo em ilhas: o caso de Fernando de Noronha (PE). Revista Brasileira de Ecoturismo, São Paulo, v.6, n.1, jan/abr-2013, pp.153-170.

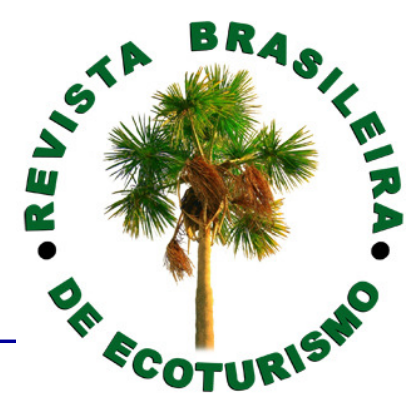

\title{
A atuação das Organizações Não-Governamentais ambientalistas no turismo em ilhas: o caso de Fernando de Noronha (PE)
}

\author{
The performance of environmental Non-Governmental Organizations on \\ island tourism: the case of Fernando de Noronha (PE, Brazil)
}

\section{Deborah da Cunha Estima, Filomena Maria Cardoso Pedrosa Ferreira Martins, Andrea Rabinovici, Maria da Anunciação Mateus Ventura}

\section{RESUMO}

Cada vez mais as ONGs ambientalistas estão desenvolvendo ações ligadas ao turismo. Essas ações têm possibilitado um aprendizado para as ONGs, para a comunidade local e pesquisadores. Contudo, verifica-se pouca profissionalização no que refere-se ao planejamento, implementação e monitoramento destas ações. Em se tratando de territórios insulares, esta relação possui características próprias, com potenciais e limitações ainda pouco explorados. Assim, a ideia de desenvolvimento sustentável, que dá base à investigação, integra as diferentes dimensões da sustentabilidade (económica, social, cultural e ambiental), transformando toda a discussão sobre o desenvolvimento do turismo. Neste artigo, derivado de dados iniciais da tese de doutorado da autora, discute-se e reflete-se as possibilidades de atuação das ONGs ambientalistas no turismo na ilha de Fernando de Noronha. Buscou-se inicialmente identificar quais as ONGs ambientalistas que atuam na ilha e seus objetivos estatutários, para proceder ao levantamento de dados que levou a caracterização sobre a atuação, as ações ligadas ao turismo, como também as potencialidades e limitações. Dessa forma, verifica-se que existe uma atuação muito forte por parte destas ONGs no turismo na llha e que, embora não haja ainda um controle sistemático dos resultados alcançados por estas ações, pode-se concluir que estas organizações possuem um importante papel no planejamento e desenvolvimento do turismo em Fernando de Noronha, participando desde as discussões sobre as medidas de ordenamento, até a capacitação da comunidade local e o monitoramento da atividade.

PALAVRAS-CHAVE: ONGs Ambientalistas; Turismo; Fernando de Noronha. 


\section{ABSTRACT}

Environmental NGOs are increasingly involved in actions linked to tourism. These actions are a two-way knowledge transfer between NGOs, local community and researchers. But the planning, implementation and monitoring of these actions, still lacks professionalization. In what concerns insular territories, this relationship has its own characteristics, with potential and limitations still unexplored. The all idea of a sustainable development underlying the research, includes the economic, social, cultural and environmental dimensions, and shapes the discussion on the course of tourism development. Here we analyze and discuss the initial data, concerning the possible interventions of environmental NGOs on tourism activity in Fernando de Noronha Island. Firstly we identified which NGOs are active on the island and what are their statutory goals, in order to characterize their actions linked to tourism, as well as their potentialities and limitations. Preliminary results show a strong role of environmental NGOs on the tourism practiced on the island, and although there is not yet a systematic control of the results achieved through these actions, they point to the existence of an important role played by these organizations on the planning and development of the tourism in Fernando de Noronha, that goes from tourism planning and monitoring to the capacity of local community.

KEYWORDS: Environmental NGO; Tourism; Fernando de Noronha.

\section{Introdução}

Cada vez mais o turismo vem-se configurando como fenômeno global fomentando transformações a nível social, ambiental e econômico. Considerado como um vetor de crescimento econômico, o turismo pode também ser visto como um indutor do desenvolvimento sustentável (SAMPAIO, 2000; PIRES et al 2002; MAZARO, 2007). Mesmo com toda a importância que possui é imprescindível adotar formas de gerir adequadamente a atividade turística para evitar ou minimizar os efeitos negativos no ambiente natural, particularmente em contextos de áreas protegidas que possuem fragilidades acrescidas, como também nos elementos referenciais e identitários das populações locais. E em se tratando de contexto insular, estes fatores, naturais e culturais, possuem maior relevância pois são considerados atrativos turísticos por excelência (BRITO, 2010). Devido ao seu grande impacto nas sociedades contemporâneas, estudos e pesquisas vêm sendo desenvolvidos com o intuito de conhecer e gerir melhor essa atividade de forma sustentável, destacando-se assim a necessidade do envolvimento dos setores público, privado e sociedade civil.

Como parte integrante da sociedade civil, as Organizações Não Governamentais (ONGs) Ambientalistas desempenham um papel de grande relevância na conservação e gestão do ambiente, atuando como facilitadores entre os governos e as comunidades locais (CALADO, 2012). Muitas destas organizações executam ações ligadas à atividade turística. Isso acontece porque o turismo desenvolve-se fundamentalmente em ambientes naturais, onde estas atuam 
diretamente, podendo contribuir de forma significativa para a sustentabilidade da atividade. A atuação das ONGs ambientalistas relacionadas ao turismo se dá pela potencialidade que esta atividade possui na conservação do ambiente e no desenvolvimento das comunidades locais. Assim, desenvolver o turismo de forma planejada e responsável é vital para os objetivos estatutários destas organizações, tornando-se um de seus mais significativos instrumentos de ação (RABINOVICl; LAVINI, 2005). Esta contribuição é realizada de várias formas: formulação de diretrizes e estratégias, monitoramento, implementação de programas e projetos de desenvolvimento sustentável alicerçados no turismo, entre outros.

A atuação das ONGs ambientalistas no desenvolvimento do turismo em destinos não é recente. Por serem consideradas guardiões da sustentabilidade nos habitats alvo das atividades turísticas, desde os anos de 1990 que elas vêm participando ativamente nas discussões relacionadas ao setor. $O$ debate e incentivo a parcerias do setor turístico com as ONGs ambientalistas para um desenvolvimento sustentável da atividade, podem ser comprovados na Conferência de Lanzarote sobre Turismo Sustentável, em 1995, na Declaração do Quebec, em 2002, nos Acordos de Mohonk em 2000, entre outros. Por serem organizações sem fins lucrativos, estas ONGs podem utilizar o turismo como uma ferramenta de viabilização financeira para os projetos de conservação do ambiente, onde as componentes de educação e desenvolvimento local são contempladas (BRITO, 2010).

Tendo em conta a importância e o crescimento desta relação, é fundamental identificar a atuação das ONGs ambientalistas relacionadas com o desenvolvimento do turismo sustentável. Mesmo sendo consideradas autônomas, estas organizações devem ser avaliadas e obrigadas a prestarem contas, nas quais a transparência nas ações e nos resultados são exigidos pelos seus financiadores, parceiros, e pela sociedade. Esta exigência faz com que as ONGs ambientalistas possam atingir assim novos patamares de eficiência organizacional, como também de responsabilidade pública (RABINOVICI; LAVINI, 2005).

Em se tratando de territórios insulares, Amaro (2010) afirma que só a partir dos anos de 1980 é que estes territórios se tornaram focos de interesse entre os investigadores fazendo surgir um campo específico de análise, particularmente no que se refere aos constrangimentos e potencialidades de desenvolvimento. Dessa forma, não é viável nem estratégico importar os modelos e propostas de desenvolvimento focadas em países continentais, sendo necessário criar quadros teóricos próprios para estes ambientes insulares. Segundo Ferreira (2008), é imprescindível haver a preocupação sobre as modalidades de desenvolvimento do turismo que contribuam de fato para o desenvolvimento sustentável, prevenindo o avolumar de efeitos negativos desta atividade nos Arquipélagos.

As ilhas oceânicas são mais vulneráveis aos efeitos das alterações climáticas, sobretudo ilhas pequenas (CALADO et al., 2011). Contudo, a comunidade científica está buscando estratégias coerentes com os objetivos de desenvolvimento do milênio, como a Declaração de Davos, visto que estas mudanças climáticas foram reconhecidas como um dos maiores desafios para o desenvolvimento sustentável do 
A atuação das Organizações Não-Governamentais ambientalistas no turismo em ilhas: o caso de Fernando de Noronha (PE)

turismo (OMT, 2009). Assim, a importância de um estudo como este tem origem na necessidade de se conhecer melhor e trazer à discussão, a efetividade destas ONGs para a melhoria do planejamento e gestão do turismo sustentável em contextos territoriais insulares. Conhecer estas realidades é imprescindível para a análise da atuação das ONGs ambientalistas, que são influenciadas diretamente pelo contexto social, político e ambiental no qual atuam, e sobretudo para partilhar informações que possibilitarão soluções mais viáveis para o planejamento e a gestão do turismo.

Ressalta-se também que a llha em estudo faz parte da Rede Mundial de Reserva da Biosfera e dos Sítios de Património Mundial classificados pela UNESCO, enfatizando assim a importância da investigação. Assim, as questões de estudo propostas são de inquestionável relevância e merecem um tratamento sério, na busca de uma nova contextualização do trabalho desenvolvido pelas ONGs ambientalistas, no âmbito do turismo.

A relevância deste tema pode ser comprovada nos diversos grupos de investigação que estão sendo criados em todo o mundo, como: United Nations Environment Programme Island (SIDS); UNESCO; IUCT World Commission on Protected Areas - Task Force on Island Conservation and Protected Areas; World Tourism Organization Network; Global Islands Network; International Small Islands Studies Association; The South Pacific Forum and the Alliance of Small Island States, Observatório Mundial das llhas, entre outros. O tema também enquadra-se nos Objetivos de Desenvolvimento do Milénio, nos quais garantir a sustentabilidade ambiental faz parte dos objetivos acordados (ONU, 2000). Dessa forma, conhecer a realidade das ONGs ambientalistas em ilhas, especificamente na llha de Fernando de Noronha, possibilitará compreender as práticas atuais e identificar as potencialidades e limitações vivenciadas por elas, que afetam diretamente as competências e contribuições para a sustentabilidade do turismo.

\section{Sustentabilidade no turismo em ilhas}

Segundo a Organização Mundial do Turismo - OMT (1999), o turismo sustentável é definido como ecologicamente sustentável, economicamente viável, de longo prazo, ética e socialmente equitativo para as comunidades locais envolvidas, onde deve existir uma integração equilibrada do meio ambiente natural, cultural e humano. Embora existam muitas definições para turismo sustentável (e.g. BUTLER, 1993; CLARKE, 1997; COLLINS, 1999; JOHNSTON AND TYRELL, 2005; OMT, 2009), para a UNEP (2005) este não representa uma forma particular de turismo. Na verdade, todas as formas de turismo deveriam ser sustentáveis, sendo responsabilidade de todos os segmentos envolvidos na atividade.

Segundo Rabinovici (2010), os conceitos de sustentabilidade, desenvolvimento e participação, devem estar presentes para os que atuam com o turismo, pois os impactos decorrentes desta atividade requerem reflexões permanentes que possam originar aprimoramentos do setor relacionados aos benefícios sociais, culturais, ambientais, e econômicos. Assim, segundo a autora, para que o turismo seja considerado sustentável deve manter a "integridade dos processos ecológicos, 
biológicos, ambientais além de satisfazer as necessidades econômicas, culturais, éticas, estéticas das pessoas e dos ambientes envolvidos" (p.5).

Para Irving e colaboradores (2005), a sustentabilidade do turismo é visto como um fenômeno complexo na sua perspectiva global. Sendo o turismo a atividade econômica que mais cresce no mundo, seu potencial como gerador de renda, benefícios econômicos, sociais e ambientais e como mecanismo para a inclusão e transformação social, faz emergir novas reflexões sobre o seu planejamento. Contudo, o turismo traz também resultados contraditórios e polêmicos onde é fundamental refletir os caminhos que o desenvolvimento desta atividade devem seguir, para delinear estratégias futuras que possam, de fato, promover o seu potencial positivo e minimizar seus impactos negativos. Dessa forma, as políticas e as ações para o planejamento do turismo devem ser delineadas numa perspetiva conjunta com a proteção do meio ambiente, sendo necessário um novo olhar sobre os problemas sociais, a diversidade cultural e a dinâmica ambiental dos destinos turísticos. Esta sustentabilidade provém assim de uma compreensão estratégica e duradoura de desenvolvimento, com base numa interpretação interdisciplinar e completa da dinâmica regional.

Neste contexto, o turismo emerge como uma das vias possíveis para o desenvolvimento local, reivindicando políticas públicas adequadas para o setor através de um planejamento integrado às políticas sociais e econômicas. A distribuição de bens figura-se como uma questão fulcral na ética da sustentabilidade do turismo (IRVING et al, 2005). Para que um projeto de desenvolvimento seja bemsucedido deve envolver a sociedade civil na elaboração e implementação de planos, programas e ações inovadoras, e possuir um enfoque local no processo de desenvolvimento (PETERSEN, ROMANO, 1999).

De acordo com Irving e colaboradores (2010), para a construção de novos paradigmas de desenvolvimento turístico sustentável é importante sensibilizar as comunidades locais, para que estas possam organizar-se e qualificar-se para a gestão sustentável desta atividade. Para isso, é necessário capacitar e investir nas potencialidades da região, discutir os riscos e benefícios que o turismo pode trazer, fomentar a identidade local e a organização social. Petersen (1999) enfatiza que um dos grandes problemas dos programas de desenvolvimento turístico está em focar no meio e não no ator social, sendo necessário conceber este ator como agente ativo em todo o processo do desenvolvimento turístico, desde o planejamento, a implementação até ao monitoramento e avaliação contínua. Nesta perspectiva, Irving (2002) afirma que o desenvolvimento sustentável do turismo impõe a inclusão de princípios e valores éticos, a democratização de oportunidades e benefícios, parcerias, co-responsabilidades e participação.

Em se tratando de contexto insular, estes destinos turísticos são vistos como símbolo de status, onde a crescente tendência à ocupação pode representar um perigo para os seus frágeis ecossistemas. As complexidades das características dos destinos insulares dão origem a uma infinidade de questões, especialmente relacionadas com o potencial de sucesso do desenvolvimento sustentável do turismo 
A atuação das Organizações Não-Governamentais ambientalistas no turismo em ilhas: o caso de Fernando de Noronha (PE)

(GRACl; DODDS, 2010). Mas esta ameaça é ainda mais grave quando há um desconhecimento sobre a dinâmica sociocultural e biofísica destes territórios, onde existem poucas pesquisas sobre o tema. Contudo, observa-se um crescente interesse por estes territórios insulares em todo o mundo, onde tem-se realizado estudos sobre a redescoberta dos ilhéus por si próprios, resultando na afirmação de suas identidades culturais através da valorização do estilo de vida muitas vezes decorrentes da invasão turística. Esta tomada de consciência de um modo de vida particular está associada a um conjunto de representações e imagens que estes ilhéus têm sobre o seu espaço geográfico-cultural, que antropólogos e geógrafos definem como "ilheidade". A ilheidade difere da insularidade, visto que este conceito respeita ao que é vivido pelos ilhéus, aos comportamentos induzidos pela natureza própria do espaço insular, algo que é diferente do isolamento, pois as ilhas não se desenvolvem em sistemas fechados, vivendo em ritmos alternados de abertura e fechamento em relação à sociedade continental (DIEGUES, 1999).

Assim, para estudar as ilhas é necessário existir um caráter interdisciplinar enfatizando as especificidades destas sociedades e territórios insulares, sendo necessário pesquisar as práticas sociais e simbólicas, as concepções de espaço, território e tempo insular (DIEGUES, 1999) ${ }^{1}$. Assim, a ilha é sempre um território particular, produzido socialmente segundo ciclos e práticas econômicas em contínua mudança, sendo um grande atrativo para o desenvolvimento do turismo, como também um grande potencial para a atuação das ONGs ambientalistas.

Neste contexto, devido as condicionantes associadas à geografia insular, às suas vulnerabilidades ambientais e aos obstáculos para alcançarem economias de escala, estas regiões têm obtido uma focalização teórica particular em várias áreas do conhecimento (AMARO, 2010). Assim, o planejamento estratégico do turismo, com o intuito de alcançar 0 desejado desenvolvimento sustentável, contribui significativamente para a mudança de base comunitária (FERREIRA, 2008). Com isso, espera-se que o turismo contribua de fato para a redução das vulnerabilidades tradicionalmente sentidas nestes espaços, indo ao encontro de necessidades socioambientais, culturais e econômicas singulares, implicando um envolvimento participativo de toda a comunidade local (BRITO, 2010).

Dessa forma, o turismo pode promover e valorizar as características e as potencialidades dos destinos turísticos do ponto de vista natural, sociocultural e econômico, compondo-se como um excelente mecanismo para minimizar os efeitos negativos à situação insular. Para além disso, reforça as identidades locais, proporcionando $\mathrm{o}$ surgimento e estímulo de sistemas participativos de desenvolvimento, como também o aparecimento de novos protagonistas. Neste contexto, é importante identificar quais as estratégias mais adequadas para a promoção do desenvolvimento a longo prazo, face à vulnerabilidade permanente com que se confrontam, originada em grande parte pelas características insulares. Assim, a estratégia do turismo alicerçado na abordagem do desenvolvimento local e participativa concilia os objetivos da sustentabilidade, contribuindo dessa forma para a inovação com mudança qualitativa das condições de vida e auxiliando o equilíbrio entre as diferentes dimensões do processo (BRITO, 2010; GRACl; DODDS, 2010). 


\section{As ONGs ambientalistas e a sustentabilidade no turismo}

Para identificar as características e os funcionamentos das ONGs ambientalistas é necessário conhecer os tipos de formas jurídicas delas. No Brasil, de acordo com o Código Civil, as ONGs ambientalistas estão enquadradas como pessoas jurídicas de direito privado, instituídas por iniciativa de particulares e têm como objetivo principal o estudo ou a defesa do meio ambiente. Estas podem ser associações ou fundações. As associações constituem-se pela união de pessoas com finalidade comum e sem fins econômicos. Já as fundações constituem-se numa universalidade de bens e direitos destinados a uma determinada finalidade social estabelecida pelo seu instituidor (BRASIL, 2002).

Existem algumas diferenças entre associação e fundação. Uma delas é que, nas associações, o núcleo central é o indivíduo, onde um grupo de pessoas se une para um determinado fim. Já nas fundações, o núcleo central é o patrimônio, onde organiza-se um conjunto de bens destinado a um objetivo determinado. Assim, para constituir uma fundação, a existência de patrimônio é uma necessidade. Outra distinção é o fim a que se destinam onde, no caso da fundação, a finalidade é permanente. Existem atualmente várias denominações que remetem a entidades de natureza privada sem fins lucrativos, mas que juridicamente são associações ou fundações. A ONG é uma destas denominações, que têm como objetivo comum lutar e apoiar causas coletivas. Contudo, é necessário haver uma ressalva, pois tais organizações podem ser utilizadas para fins de minorias privilegiadas (INSTITUTO PRO BONO, 2005).

No Brasil, a importância das ONGs ambientalistas e a ideia de desenvolvimento sustentável propagaram-se de forma mais visível após a II Conferência Mundial para o Meio Ambiente e Desenvolvimento Sustentável (Rio-92), na qual o discurso sobre negócios sustentáveis foi bastante difundido. Este discurso fez com que os ambientalistas vissem no turismo um instrumento de conservação da natureza, através de ações estratégicas que valorizam o património natural, reconhecem os limites do seu crescimento e procuram a participação social. Para além disso, o turismo é uma excelente ferramenta de educação ambiental alcançando mudanças de valores, comportamentos e atitudes dos atores envolvidos na atividade. Esta ênfase é observada no aumento de projetos propostos por instituições, empesas, e também pelas ONGs (BRITO, 2010; RABINOVICI, 2010).

Vários documentos oficiais nacionais e internacionais validam a importância e o papel das ONGs no desenvolvimento do turismo sustentável. Devido a pouca influência de políticas públicas e iniciativas privadas, como também a forma descontínua das ações ligadas ao turismo, as ONGs passam a ter uma participação mais efetiva nesta área, onde possuem uma importância decisiva para a sustentabilidade da atividade turística (LAVINI, 2002; SERRANO, 2005, GRACI; DODDS, 2010). Assim, as ONGs passam a ser aceitas como participantes e interlocutoras na gestão do turismo legitimando as ações como democráticas e participativas (RABINOVICI; FERREIRA, 2008).

O turismo e as ONGs são usualmente vistos pela sociedade em geral como 
A atuação das Organizações Não-Governamentais ambientalistas no turismo em ilhas: o caso de Fernando de Noronha (PE)

salvadores, pois prometem alternativas de mudanças, sejam elas sociais e/ou ambientais. Contudo, existem vários exemplos que contradizem esta visão, tornando-se necessário repensar as concepções e estratégias dos projetos de turismo propostos pelas ONGs. Assim, os métodos e as ferramentas participativas utilizados por estas organizações devem ser revistos no intuito de contribuir para a sustentabilidade das ações de turismo, legitimando assim suas iniciativas (RABINOVICI, 2009). Consideradas atores do desenvolvimento do turismo, é necessário que as ONGs se posicionem de maneira eficiente e suficiente no que diz respeito à proteção e à valorização do património turístico das ilhas, à sensibilização sobre as práticas responsáveis de turismo, à medição e avaliação dos impactos da atividade, à certificação do turismo, entre outros (BRITO, 2010).

A participação da comunidade local é um consenso para a sustentabilidade do turismo, mas muito limitada pelas dificuldades prática, operacional e metodológica. Embora as ONGs busquem esta sustentabilidade, existem algumas limitações que restringem, em grande parte, o alcance dos resultados participativos. Sendo as ONGs consideradas agentes catalisadoras de ações de conservação ambiental, podem desmobilizar as iniciativas locais, onde a comunidade passa a depender da sua proteção, e que muitas vezes não fazem sentido para elas. A base desta proteção pode ser real, mas pode ser uma atitude preconceituosa ou estar ligada a interesses das ONGs. Assim, a realidade demonstra que o turismo e o mau uso dos processos participativos podem configurar-se como ameaça e risco, sendo necessário investigar e acompanhar o poder que as ONGs possuem no debate sobre a sustentabilidade socioambiental, que pode gerar novas desigualdades e conflitos, mas também novos graus de participação e empoderamento dos atores envolvidos com a gestão dos recursos naturais (RABINOVICI, 2010).

Assim, mesmo com todas as diferenças, é necessário que as ONGs, ao decidirem trabalhar com o turismo, estejam cientes dos limites existentes ao proporem ligações entre realidades distintas, como também a fomentarem sonhos e projetos complexos às comunidades envolvidas. Neste sentido, já existe um certo volume de história das trajetórias percorridas pelas ONGs e comunidades na tentativa de desenvolverem o turismo sustentável, que é importante ser avaliado, repensado e reorientado. Dessa forma, é necessário analisar estas mudanças na intenção de melhorar as práticas e concepções, criando diferentes instrumentos e ferramentas de monitoramento e avaliação das mudanças sociais, ambientais e de participação, capazes de conduzir à sustentabilidade do turismo. Assim, o turismo e as ONGs são dotados de potencial para desenvolver novas dinâmicas e projetos, mas ainda têm muito a aprender, pois o caminho ideal decorre de uma contínua prática reflexiva que assimile todos os conhecimentos e contribuições (RABINOVICI, 2010).

\section{Atuação das ONGs ambientalistas no turismo sustentável em Fernando de No- ronha (PE)}

O Arquipélago de Fernando de Noronha (FN) é formado por 21 ilhas, ilhotas e rochedos, ocupando uma área de $26 \mathrm{~km}^{2}$ no Oceano Atlântico. Constitui-se como o Distrito Estadual de Pernambuco desde 1988, quando deixou de ser um território Federal do Brasil. A única ilha habitada, FN, é gerida por um administrador-geral designado pelo 
Governo de Pernambuco, e tem $17 \mathrm{~km}^{2}$, ficando a $545 \mathrm{~km}$ de Recife, capital do Estado (ADM\&TEC, 2000; CARVALHO, 1999).

A Administração da llha é da responsabilidade do Estado de Pernambuco, mas outros atores são corresponsáveis pela gestão do espaço, como os gestores das duas áreas protegidas: o Parque Nacional Marinho (PARNAMAR) e a Área de Proteção Ambiental (APA) de FN (BRASIL, 2000). O turismo em FN iniciou por volta de 1959 e em 2001 a llha foi reconhecida como de importância mundial para a preservação dos patrimônios históricos e naturais pela Organização das Nações Unidas para a Educação, a Ciência e a Cultura (UNESCO, 2012; MMA, 2005; ADM\&TEC, 2000).

Atualmente, o turismo é a principal atividade econômica da llha, sendo por isso necessário compreender, planejar e monitorar os impactos, positivos e negativos, desta atividade, para controlar o desenvolvimento de FN. Em 2012 existem três ONGs ambientalistas atuando na Ilha: a Fundação Centro Brasileiro de Proteção e Pesquisa das Tartarugas Marinhas (Fundação Pro-Tamar); o Centro Golfinho Rotador; e o Instituto Ambiental de FN (IAFENO).

Como o objetivo da investigação é identificar as características e a atuação das ONGs ambientalistas na sustentabilidade do turismo em FN, a população estudada é composta por todas as ONGs ambientalistas existentes na Ilha. Neste caso, o objetivo é atingir toda a população, não delimitando uma amostra, que possibilitará uma análise mais detalhada da realidade local, permitindo identificar o porquê delas optarem ou não por desenvolver ações ligadas ao turismo e como contribuem para a sustentabilidade desta atividade.

Para o alcance dos objetivos referenciados, foi realizada pesquisa bibliográfica e documental no sentido de explorar o eixo temático central e conhecer a literatura existente sobre o tema investigado. Para complementar a investigação, procedeu-se a pesquisa empírica, por meio de entrevistas estruturadas com os responsáveis legais pelas ONGs, como também entrevistas abertas com funcionários e/ou estagiários destas organizações que desenvolvem diretamente atividades ligadas ao turismo².

\section{Atuação das ONGs ambientalistas em Fernando de Noronha}

Sobre a atuação da Fundação Pro-Tamar em FN, Robles (em entrevista à autora em 19/01/2012) ${ }^{3}$ diz que para chegar ao objetivo geral, esta tem passado por várias atividades, desde a sua fundação até hoje. Informa que na base de FN as ações da ONG estão distribuídas em três vertentes: pesquisa e conservação; trabalho de inclusão social; e educação ambiental. Sobre estas atividades, ele explica que a pesquisa e conservação resumem-se ao trabalho de campo e científico. $O$ de trabalho e inclusão social diz respeito aos grupos produtivos formados pela comunidade local onde o Tamar apoia, às capacitações e cursos que a ONG disponibiliza, e também ao apoio à cultura local. Já a educação ambiental tem como público-alvo a comunidade local e os turistas, onde destacam-se as atividades de turismo participativo. Justificando o porquê da atuação da ONG na llha, refere que o Tamar iniciou suas 
A atuação das Organizações Não-Governamentais ambientalistas no turismo em ilhas: o caso de Fernando de Noronha (PE)

atividades em FN em 1984 devido a esta ser uma das poucas áreas onde a tartaruga verde desova. Por ser uma espécie ameaçada de extinção, é de suma importância proteger estas áreas e consequentemente a espécie.

Em relação a atuação do Centro Golfinho Rotador em FN, Medeiros (em entrevista à autora em 23/01/2012) ${ }^{4}$ informa que existem várias etapas. A primeira, que é a mais antiga, é a pesquisa científica através do monitoramento dos golfinhos rotadores na Ilha. Afirma ainda que, os resultados destes estudos podem auxiliar os órgãos ambientais no planejamento e gestão das áreas protegidas. A segunda é a educação ambiental, onde desenvolve trabalhos com as crianças sobre a importância da conservação de $\mathrm{FN}$ como um todo. A terceira parte é o desenvolvimento comunitário, no qual existe uma relação mais próxima com o turismo através das capacitações, palestras, entre outras ações. Sobre esta capacitação, diz que o foco está nos moradores, pois o objetivo é capacitar a população local para suprir uma necessidade que o turismo exige na llha. Ela enfatiza que um dos grandes problemas da llha é o crescimento populacional, que é limitado principalmente por estar dentro de duas áreas protegidas. Ainda sobre esta questão, como a ONG necessita de pessoas capacitadas para desenvolver as suas ações, o fato de trazer pessoas de fora agrava ainda mais esta situação. Assim, a ONG tem uma ação que é a capacitação dos moradores para ocuparem postos de trabalho na área do turismo e do ambiente. Explicando a atuação da ONG na llha, informa que tudo iniciou com a grande concentração de golfinhos rotadores e o crescente aumento do número de turistas, que levou a uma grande preocupação de preservar esta espécie e o meio ambiente.

\section{Atuação das ONGs ambientalistas no turismo}

Ao questionar sobre se a Fundação Pro-Tamar atua com o turismo em algum dos seus projetos, verificou-se que sim, onde Robles (em entrevista à autora em 19/01/2012) afirma que os motivos que levam esta ONG a exercer ações ligadas ao turismo têm como base fazer com que as pessoas conheçam a importância de preservar as tartarugas e, sensibilizadas, ajudarem na sua conservação. A ONG não possui nenhum projeto específico de turismo. Contudo existem os centros de visitantes, que são considerados também como os museus, e que podem ser classificados como um programa dentro da Fundação. O funcionamento dos centros de visitantes possui uma gestão específica, com centros de custos próprio, e é tido como um programa contínuo com ligação às atividades de educação ambiental. Para além dos centros de visitantes, também existem os programas de turismo participativo, ou atividades abertas. Uma dessas atividades é o acompanhamento das aberturas de ninho que é bastante procurada pelos turistas, e que a ONG já desenvolve há mais de 10 anos.

Ainda sobre esta atuação ligada ao turismo, Robles (em entrevista à autora em 19/01/2012) realça que a base de Noronha foi a pioneira na realização de parcerias com universidades de turismo no Brasil, e afirma que foi uma novidade para o setor jurídico da Fundação, que geralmente só realiza convênios com estudantes de biologia. Essa parceria funciona da seguinte forma: como parte da formação 
acadêmica, os alunos vão estagiar durante três meses na base do Tamar em FN. Durante este período é obrigatório, para além das atividades executadas diariamente na base, desenvolver um artigo sobre as ações da ONG e a atividade turística. Enfatiza que esta ação está sendo muito proveitosa para a ONG devido a oportunidade da partilha de experiências entre os funcionários e estagiários.

Sobre a atuação do Centro Golfinho Rotador em projetos ligados ao turismo em FN, Medeiros (em entrevista à autora em 23/01/2012) declara que não desenvolve nenhuma atividade específica para o turista, mas salienta que a ONG tem uma relação direta através das suas ações com a intenção de disponibilizar informações aos turistas, durante as ações de pesquisa realizadas pela equipe. Um exemplo ocorre durante o monitoramento dos golfinhos rotadores na Bahia dos Golfinhos. Outra ação ligada ao turismo são as palestras gratuitas disponibilizadas todas as segundas-feiras no auditório da Fundação Pro-Tamar, que é uma das formas de mostrar os resultados alcançados ao longo dos 21 anos que a ONG atua na Ilha. Identificando os motivos que levam a ONG a desenvolver ações com o turismo, salienta que a informação tem que ser difundida e que no Mirante dos Golfinhos passam muitas pessoas interessadas em conhecer mais sobre a espécie golfinho rotador. Para ela, é de suma importância esse contato com os visitantes para difundir todo o trabalho realizado. Explica que a ONG atua muito mais na medida de conservação através dos estudos, contribuindo assim para o planejamento e a gestão do turismo na llha.

\section{Ênfase das propostas dos projetos turísticos desenvolvidos}

Foram questionados aos responsáveis legais das ONGs investigadas quais ênfases são dadas aos projetos/ações turísticos desenvolvidos pelas ONGs ambientalistas em FN. Foi solicitado identificar o grau de cada uma como de máxima, considerável e mínima, importância. Para isso, foram pré-elencados alguns tópicos. Em relação à Fundação Pro-Tamar, verifica-se que ter uma ação nacional, como o Título de Capitalização Tamar do Banco Bradesco, como também ter ações locais, como os projetos locais, possuem grau de importância máxima. Da mesma forma, no que diz respeito a contribuir para as políticas públicas, promover o aumento quantitativo e qualitativo no debate das questões ambientais, a preservação e a conservação do ambiente e a sustentabilidade do turismo na llha, salienta que é de máxima importância para o Tamar.

Para Robles (em entrevista à autora em 19/01/2012), possuem relevância intermediária os seguintes tópicos: promover a integração entre comunidade local e turistas; o desenvolvimento econômico e social da comunidade; a cultura e manifestações artísticas locais; e o comprometimento político da sociedade de maneira integrada. Destacou também que promover a integração entre comunidade local e turistas ainda é considerada intermediária, mas que estão buscando implementar ações para que possa vir a ter máxima importância.

Para o Centro Golfinho Rotador, verifica-se que ter uma ação pontual possui um grau de importância máxima. Medeiros (em entrevista à autora em 23/01/2012) 
A atuação das Organizações Não-Governamentais ambientalistas no turismo em ilhas: o caso de Fernando de Noronha (PE)

explica que por ser uma ONG local, e devido às particularidades da llha, principalmente por ser o único lugar do Atlântico Sul em que aparece a espécie golfinho rotador, e ainda pelo grande volume de turistas (70 mil por ano), existe uma grande preocupação em afetar o ambiente o menos possível. Também possui máxima importância contribuir para as políticas públicas, pois a ONG é membro dos Conselhos existentes na llha (APA, PARNAMAR e de Turismo), nos quais são discutidos os assuntos relacionados às políticas públicas locais. Promover o aumento quantitativo e qualitativo no debate das questões ambientais também possui máxima importância, e é enfatizado que estão implantando na llha um programa de gestão sustentável para as pousadas, sendo também desenvolvido nas instalações da ONG. Promover a preservação e a conservação do ambiente, também possui máxima importância, sendo esta uma das principais atuações da ONG. Também como máxima importância estão a promoção da sustentabilidade do turismo na llha, do desenvolvimento econômico e social da comunidade e da cultura e manifestações artísticas locais.

Sobre o grau de importância em ter uma ação nacional, Medeiros (em entrevista à autora em 23/01/2012) afirma que é de considerável importância, pois a ONG participa em fóruns nacionais onde são discutidas medidas de regulamentação que interferem diretamente nas ações de preservação realizadas pelo Centro na llha. A promoção da integração entre a comunidade local e os turistas, e o comprometimento político da sociedade de maneira integrada, também são percebidos como de considerável importância.

\section{Vantagens e limitações em desenvolver ações ligadas ao turismo}

Segundo Robles (em entrevista à autora em 19/01/2012), uma das vantagens em desenvolver ações ligadas ao turismo para a Fundação Pro-Tamar é: "das pessoas conhecerem o nosso trabalho. Não é nem o nosso trabalho, é a tartaruga né. O animal e a importância dele". Quanto a limitações, esclarece que a falta de conhecimento técnico ligado ao turismo é um grande entrave, mas que a ONG já está minimizando esta questão com convênios com estudantes de turismo.

Para o Centro Golfinho Rotador, Medeiros (em entrevista à autora em 23/01/2012) afirma que uma das vantagens é que: "de certa forma a gente consegue controlar o turismo que seria a atividade mais impactante da liha. A gente vai estar diretamente relacionada com a conservação". E explica que a grande limitação está relacionada com a necessidade de ter pessoas qualificadas para trabalhar no Centro, sendo este um agravante para o crescimento populacional da llha, que a ONG tenta minimizar através da capacitação profissional disponibilizando estágios para alunos das escolas locais. Outra limitação colocada é a questão da necessidade de sempre estar buscando recurso financeiro para desenvolver as atividades da ONG.

\section{Como auxiliar no planejamento e gestão da atividade turística}

Em relação à Fundação Pro-Tamar, Robles (em entrevista à autora em 19/01/2012), diz que as ONGs ambientalistas podem auxiliar no processo de 
planejamento e gestão da atividade turística na llha. E informa que, para além de dever ajudar, elas já auxiliam. Quando questionado sobre a forma como são realizados esses auxílios, o mesmo informou que ajudam nas discussões sobre o planejamento e a gestão do turismo, possuem voz ativa nos conselhos e nos grupos de discussão. Para além disso, também contribui realizando atividades turísticas gratuitas.

Para o Centro Golfinho Rotador, Medeiros (em entrevista à autora em 23/01/2012), informa que as ONGs ambientalistas podem sim auxiliar no processo de planejamento e gestão da atividade turística na Ilha. Para ela as ONGs em FN estão bastante envolvidas no turismo, principalmente fornecendo informações adequadas através das pesquisas.

\section{Percepção e desafios para a sustentabilidade do turismo}

Para a Fundação Pro-Tamar, Robles (em entrevista à autora em 19/01/2012) afirma que o turismo ainda está em equilíbrio, mas acredita que poderia ser melhorado através de um planejamento mais participativo da atividade turística, como também de uma sensibilização sobre o que é de fato a sustentabilidade.

Para o Centro Golfinho Rotador, Medeiros (em entrevista à autora em 23/01/2012) diz que a sustentabilidade ainda é recente na llha, mas que já existem ações pontuais como a feira de sustentabilidade.

\section{Equilíbrio entre a atividade turística e a preservação ambiental}

Para a Fundação Pro-Tamar, Robles (em entrevista à autora em 19/01/2012) declara que existe equilíbrio entre a atividade turística e a preservação ambiental em FN. Para justificar esta afirmativa, ele explica que o melhor exemplo é o título que a Ilha ganhou como Patrimônio Mundial da Natureza.

Para o Centro Golfinho Rotador, Medeiros (em entrevista à autora em 23/01/2012) afirma que existe sim equilíbrio entre a atividade turística e a preservação ambiental na Ilha. Ela explica que a ONG sempre acreditou que o turismo pode estar voltado para a preservação do ambiente, como por exemplo através da observação de cetáceos.

\section{Contribuição das ONGs para a sustentabilidade do turismo}

Segundo Robles (em entrevista à autora em 19/01/2012), a Fundação ProTamar pode trazer contribuições para a sustentabilidade associada à atividade turística em FN através das atividades gratuitas que geram renda e sensibilizam a comunidade local e os turistas.

Para Medeiros (em entrevista à autora em 23/01/2012), a contribuição que o Centro Golfinho Rotador traz está relacionada com a ação de sustentabilidade junto às pousadas na Ilha, através da certificação ambiental, a qual irá diminuir o impacto causado pelo turismo. 
A atuação das Organizações Não-Governamentais ambientalistas no turismo em ilhas: o caso de Fernando de Noronha (PE)

\section{Considerações finais}

Verifica-se que a atuação das ONGs ambientalistas investigadas possui relação direta e indireta com o turismo em FN, seja através de ações que envolvam a comunidade local como o apoio e valorização da cultura local, apoio a grupos produtivos, educação ambiental (sensibilização), capacitação, contratação de mão-deobra, qualificação dos empreendimentos (certificação), seja através do contato direto com o turista. Em relação às ações ligadas diretamente ao turismo destacam-se os programas de turismo participativo, as palestras e as informações disponibilizadas aos turistas durante as ações de preservação das ONGs. Embora as ações sejam disponibilizadas gratuitamente, apenas uma ONG agencia serviços turísticos (Tartarugadas). As ONGs investigadas também contribuem para as políticas públicas do ambiente, do turismo e de desenvolvimento da llha. Contudo, não existem projetos específicos de turismo e sim ações.

Em relação às ênfases dadas aos projetos turísticos desenvolvidos pelas ONGs ambientalistas na llha, verifica-se que o turismo possui uma elevada importância, fato que corrobora para as ações que as mesmas vêm desenvolvendo. Consequência disso é a percepção dos responsáveis destas ONGs que acreditam que uma das vantagens em desenvolver ações ligadas ao turismo é a possibilidade dos turistas conhecerem os trabalhos realizados por elas e assim poderem estar mais sensibilizados e contribuir para a valorização e a preservação do meio ambiente, especificamente das espécies golfinho rotador e tartaruga. Também é considerada uma vantagem poder contribuir para o controle da atividade turística através das pesquisas realizadas, auxiliando assim no processo de planejamento e gestão da atividade.

Em relação à percepção dos responsáveis pelas ONGs investigadas sobre a sustentabilidade associada à atividade turística na llha, verifica-se que eles acreditam que está em equilíbrio, embora seja necessário fazer muito mais, como é o caso da destinação dos resíduos produzidos. Afirmam que essa é uma questão que ainda é inicial e que é imprescindível um planejamento mais bem elaborado do turismo onde haja de fato uma participação mais engajada de todos os setores. Quanto ao equilíbrio entre a atividade turística e a preservação ambiental na llha, todos concordam que é possível e que existe este equilíbrio, validando a importância do turismo para o destino e para as ONGs investigadas. Neste contexto, eles acreditam que, por serem ONGs ambientalistas, podem trazer contribuições para a sustentabilidade do desenvolvimento do turismo através da disponibilização de atividades e sensibilização voltadas aos turistas de forma gratuita, geração de emprego e renda, qualificação dos setores envolvidos na atividade, como também auxiliando na regulamentação do setor através das investigações.

Dessa forma, verifica-se que existe uma atuação muito forte por parte destas ONGs ambientalistas no turismo na llha e que, embora não haja ainda um controle sistemático dos resultados alcançados por estas ações, pode-se concluir que os resultados iniciais alcançados indicam que estas organizações possuem um importante papel no planejamento e desenvolvimento do turismo em FN, participando 
desde as discussões sobre as medidas de ordenamento do turismo, até à capacitação da comunidade local e ao monitoramento da atividade. Contudo, é necessário realizar estudos mais aprofundados para identificar o nível de participação da comunidade local nestas ações desenvolvidas pelas ONGs ambientalistas, como também a inclusão e transformação social local.

Dessa forma, estes dados iniciais incidem sobre questões científicas originais e relevantes que contribuirão para a promoção do avanço do conhecimento científico e para o desenvolvimento de políticas públicas do turismo em contextos insulares. Neste sentido, o desenvolvimento sustentável do turismo em ilhas é um processo complexo e de longa duração que requer o apoio de vários atores, onde a atuação das ONGs ambientalistas possui um relevante papel para atingir esta sustentabilidade. Observa-se que estas organizações possuem cada vez mais poder na sociedade e, embora seja do conhecimento geral o envolvimento das ONGs ambientalistas em ações ligadas ao turismo, há ainda um relativo desconhecimento sobre o modo como é realizada esta atuação e até que ponto elas estão contribuindo para o desenvolvimento sustentável do turismo nos destinos insulares nos quais estão inseridos. Assim, conhecer esta realidade será fundamental para elaborar estratégias de atuação que respeitem a diversidade cultural e necessidades específicas das ilhas, destacando as iniciativas positivas emergentes e fornecendo um recurso valioso que irá aumentar a conscientização da importância da atuação das ONGs ambientalistas para a sustentabilidade da atividade turística.

\section{Referências bibliográficas}

ADM\&TEC. Plano de Gestão do Arquipélago de Fernando de Noronha, Ecoturismo e Desenvolvimento Sustentável. Fase I: Capacidade de suporte. Etapa: Relatório Final. Recife, 2000.

AMARO, R. Prefácio. In: BRITO, B. Turismo em Meio Insular Africano: Potencialidades, constrangimentos e impactos. Série Estudos. Lisboa: Gerpress, 2010.

BLUTLER, R. Tourism: an Evolutionary Perspective. In: NELSON, J. G., BUTLER, R. and WALL, G. (eds) Tourism and Sustainable Development: Monitoring, Planning and Managing. Department of Geography Publication Series n.37. Waterloo: University of Waterloo, 1993

BRASIL. Lei 10.406, de 10 de Janeiro de 2002. Código Civil Brasileiro. Presidência da República, 2002.

BRITO, B. R. Turismo em Meio Insular Africano. Potencialidades, constrangimentos e impactos. Lisboa: Gerpress, 2010.

CALADO, H., BENTZ, J., NG, K., ZIVIAN, A., Schaefer, N., Pringle, C., Johnson, D., Phillips, M. NGO involvement in marine spatial planning: A way forward? Elsevier Ltd. Marine Policy, n36, p.382-388, 2012.

CARVALHO, L. F. A. Impactos do Turismo no Arquipélago de Fernando de Noronha: um estudo no caminho do desenvolvimento sustentável. Monografia do Curso de 
A atuação das Organizações Não-Governamentais ambientalistas no turismo em ilhas: o caso de Fernando de Noronha (PE)

Turismo, Universidade de São Paulo, Escola de Comunicações e Artes, Departamento de Relações Públicas, Propaganda e Turismo, 1999.

CLARKE, H. Australian tourism industry policy: a new view. Tourism Economics, 3(4): 361-77, 1997.

COLLINS, A. Tourism development and natural capital. Annals of Tourism Research, 26 (1): 98-109, 1999.

DIEGUES, A. C. Sociedades Insulares e Biodiversidade. NUPAUB-USP, 1999.

FERREIRA, E. M. O turismo sustentável como factor de desenvolvimento das pequenas economias insulares: o caso de Cabo Verde. Lisboa: Lusófonas, 2008.

GRACI, S. e DODDS, R. Sustainable Tourism in Island Destinations. Tourism, Environment and Development Series. London: Earthscan, 2010.

INSTITUTO PRO BONO. Manual do Terceiro Setor. São Paulo, 2005.

IRVING, M. A. Turismo, ética e educação ambiental - novos paradigmas em planejamento In: IRVING, M. A. e AZEVEDO, J. Turismo: o desafio da sustentabilidade. São Paulo: Futura, 2002.

IRVING, M. A.; BURSZTYN, I.; SANCHO, A. P.; MELO, G. M. Revisitando significados em sustentabilidade no planejamento turístico. Caderno Virtual de Turismo, vol. 5, núm. 4, 2005, pp. 1-7, Universidade Federal do Rio de Janeiro, Rio de Janeiro, Brasil, 2005.

JONSTON, R. J. and TYRELL, T. J. A dynamic model of sustainable tourism. Journal of Travel Research, 2(44): 124-34, 2005.

LAVINI, C. Ecoturismo e Terceiro Setor: atuação de ONGs ambientalistas do Estado de São Paulo. Trabalho de Conclusão de Curso (TCC) (Graduação em Turismo). Departamento de Relações Públicas, Propaganda e Turismo da Escola de Comunicações e Artes - USP, São Paulo, 2002.

MAZARO, R. A sustentável leveza do visitar: modelo de avaliação de competitividade e sustentabilidade estratégica dos destinos turísticos. Revista Turismo: Visão e Ação, 9 (3), 2007.

MMA. Plano de Manejo da APA Fernando de Noronha - Rocas - São Pedro e São Paulo. Ministério do Meio Ambiente, Instituto Brasileiro do Meio Ambiente dos Recursos Naturais Renováveis, 2005.

OMT. Código Mundial de Ética para o Turismo. Madrid, 1999.

OMT. From Davos to Copenhagen and Beyond - advancing tourism's response to climate change. 2009.

ONU - Organização das Nações Unidas. Objetivos de Desenvolvimento do Milénio, 2000.

PETERSEN, P. Participação e desenvolvimento agrícola participativo: uma visão estratégica com ênfase na etapa do diagnóstico. In: PETERSEN, P.; ROMANO, J.O. (Orgs.) Abordagens participativas para o desenvolvimento local. Rio de Janeiro: ASPTA/ Actionaid Brasil, 1999.

PETERSEN, P. e ROMANO, J. O. Abordagens participativas para o desenvolvimento local. Rio de Janeiro: AS-PTA/Actionaid Brasil, 1999.

PIRES, P., GUEDES, L., EXEQUIEL, L., GERHARDT, R. Turismo sustentável: Planejamento turístico e atividades acadêmicas na região sul do município de Balneário 
Camboriú, Revista Turismo: Visão e Ação, 4(9), pp.93-99, 2002.

RABINOVICI, A., 2010. Organizações Não Governamentais e a Sustentabilidade do Turismo. V Encontro Nacional da ANPPAS, 4 a 7 de outubro de 2010, Florianópolis - SC - Brasil.

RABINOVICI, A., LAVINI, C., 2005. ONGs - Ecos de um Turismo Sustentável. In: NEIMAN, Z. e MENDONÇA, R. Ecoturismo no Brasil. Barueri- SP, Ed. Manole, pp.1-18, 2005.

RABINOVICI, A; FERREIRA, L. C. Organizações Não Governamentais e Turismo Sustentável: participação e conflitos. Anais IVo ENANPPAS - Encontro da Associação Nacional de Pesquisa e Pós-Graduação em Ambiente e Sociedade, Brasília, junho de 2008.

RABINOVICI, A. Organizações Não Governamentais e Turismo Sustentável: trilhando conceitos de participação e conflitos. 2009. 340 p. Tese (Doutorado em Ambiente e Sociedade) - NEPAM - UNICAMP, Campinas, SP.

SAMPAIO, C., 2000. Gestão organizacional estratégica para o desenvolvimento sustentável: Uma metodologia alternativa para o planejamento turístico sustentável. Revista Turismo: Visão e Ação, 2(6), pp.97-118, 2000.

SERRANO, C. M. T. Uma introdução à discussão sobre turismo, cultura e ambiente e a vida e os parques: proteção ambiental, turismo e conflitos de legitimidade em Unidades de Conservação. In: SERRANO, C.M.T.; BRUHS, H.T. (Org.). Viagens à natureza: turismo, cultura e ambiente. 7 ed. Campinas: Papirus, pp. 11-26 e pp. 103-124, 2005.

UNEP. Making Tourism Sustainable: a guide for policy makers. Paris: UNEP, 2005.

UNESCO. Disponível em: (http://www.unesco.org/new/pt/brasilia/culture/world-heritage/list -of-world-heritage-in-brazil/) Acesso: 29 Abr. 2012.

\section{Agradecimentos}

Agradecemos todo o apoio disponibilizado pela Administração da llha de Fernando de Noronha para a realização desta investigação, como também às ONGs ambientalistas investigadas, ao Instituto Recifes Costeiros, ao ICMBio, ao PARNAMAR e à APA de Fernando de Noronha.

Esta investigação faz parte da tese de Doutorado financiado pelo Fundo Regional de Ciência e Tecnologia - FRCT (Governo dos Açores) M3.1.2/f/042/2011.

\section{Notas:}

${ }^{1}$ Embora de inquestionável valor, não será detalhado o estudo das sociedades insulares no que se refere aos aspectos simbólicos e suas representações neste artigo, visto ser uma abordagem diferenciada da que é proposta na investigação. Mas é necessário mencionar a importância desta linha de pesquisa, como também o caráter interdisciplinar quando se estuda ambientes insulares.

2 No período de aplicação da investigação, fevereiro de 2012, não foi possível obter dados sobre a ONG IAFENO, pois não foi identificada nenhuma estrutura física, e existe um certo desconhecimento sobre esta ONG pela comunidade, para além de que o responsável legal estava fora da llha. 
A atuação das Organizações Não-Governamentais ambientalistas no turismo em ilhas: o caso de Fernando de Noronha (PE)

${ }^{3}$ Rafael Robles é o Coordenador da Base da Fundação Pró-Tamar em Fernando de Noronha.

${ }^{4}$ Priscila Izabel de Medeiros é Coordenadora Executiva do Centro Golfinho Rotador em Fernando de Noronha.

Deborah da Cunha Estima: Universidade de Aveiro, Aveiro, Portugal.

Email: deborahestima@hotmail.com

Link para o currículo Lattes: http://lattes.cnpq.br/4668908614613394

Filomena Maria Cardoso Pedrosa Ferreira Martins: Universidade de Aveiro, Aveiro, Portugal.

Email: filomena@ua.pt

Link para o currículo: http://www.cesam.ua.pt/index.php?tabela=pessoaldetail\&menu $=81 \&$ user $=53$

Andrea Rabinovici: Universidade Federal de São Paulo, Diadema, SP, Brasil.

Email: andrearabinovici@gmail.com

Link para o currículo Lattes: http://lattes.cnpq.br/4506171831521594

Maria da Anunciação Mateus Ventura: Universidade dos Açores, Açores, Portugal.

Email:mateus@uac.pt

Link para o currículo: http://www.cibio.inazores.me/index.php/effective-members/14-em -mariaanunciacaoventura

Data de submissão: 28 de junho de 2012

Data de recebimento de correções: 19 de novembro de 2012

Data do aceite: 19 de novembro de 2012

Avaliado anonimamente 